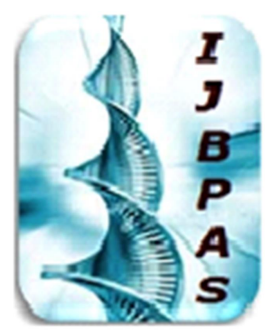

International Journal of Biology, Pharmacy and Allied Seiences (IJBPAS) 'A B Bridge Betusen Caboratory and Qpadto'

WwW.iibpas.com

\title{
A RETROSPECTIVE ANALYSIS ON DRUG USAGE PATTERN OF GERIATRIC PATIENTS IN A TERTIARY CARE CENTER
}

\section{BRIGIDA S*, SOUJANIA SINGH G AND ARUL AMUTHA ELIZABETH} Department of Pharmacology, Sree Balaji Medical College and Hospital, Chrompet, Chennai *Corresponding Author: Dr. S. Brigida: E Mail id : $\underline{1506 d r . b r i g i d a @ g m a i l . c o m ~}$

Received 25 ${ }^{\text {th }}$ March. 2021; Revised 26 ${ }^{\text {th }}$ April 2021; Accepted 22 ${ }^{\text {nd }}$ May 2021; Available online $1^{\text {st }}$ Dec. 2021 https://doi.org/10.31032/IJBPAS/2021/10.12.5790

\begin{abstract}
Background: Geriatric population are the most vulnerable population for multiple drug regimen and ill-suited prescriptions. These preeminent multiple drug regimen suggestion in elderly patients may be of patient or physician origin. Beer's criteria have been developed to evaluate and to help in the reduction of potentially ill-suited drug suggested to elderly patients. Objective: The current study was done to analyse the details regarding drugs prescribed for aged above 60 in in and outpatients of a medical college hospital and to evaluate its suitability according to the Beer's criteria. Materials \& Methods: This retrospective study was conducted in Sree Balaji Medical College \& Research Hospital from February 2020 to January 2021. A total of 1600 admission and prescription details in records of in and outpatients of $\geq 60$ years in surgical, medical, and orthopaedic wards and OPD were reviewed. Pertinent details were recorded in a pre-designed format\& data was evaluated.

Results: The major proportion of case records shows the patients were suffering from Infectious disorder (28\%) next in line were cardiovascular system (19\%). The prescription details of drugs revealed majority had antibiotics (28\%). Multiple drug regimens were prescribed for $49.6 \%$ patients. According to Beer's criteria, 605 drugs were not found in appropriate suitability to the elderly population and the rationale of which cannot be corelated which is of most concern in this study population. Conclusion: This analysis on prescriptions gave a glimpse of pattern of ailments, infirmities in older patients, the drugs used to treat them and detected the lacunae in prescription suitability in elderly. This also found multiple drug regimens prescribed were comparatively high, despite of many reasons to substantiate its unavoidability there is a pressing need to reduce it in future by relevant measures of interdisciplinary approach.
\end{abstract}

Keywords: Prescription pattern in geriatric population, multiple drug regimen (polypharmacy) 


\section{INTRODUCTION}

Population census 2011, predicted India's geriatric population (aged 60 and above) will grow to 173 million by 2026 . Pharmacy interventions to cater this group will remain a challenge, reason being i) most of them have multiple ailments ii) Most of them take drugs suggested by their walk mates or relatives which they have taken and cured of ailments (without even physician consultation) iii) fond of Ayurveda and siddha preparations which they usually hide when consulting allopathy doctors, ultimately ended in inappropriate prescriptions and polypharmacy. Drug utilization pattern studies are probing tool in finding the role of drug for sustainability of healthy life among the population.

Geriatric prescription is usually a genuine challenge as the physician need to satisfy the patient as well as he need to treat their ailment considering the drug-drug interaction. The change in absorption, distribution, metabolism and excretion pattern in elderly, patient to patient variation in acceptability of drugs makes the physician so keen in prescribing medicines, also the prescribing pattern itself shows their competence and excellence in patient care. Inappropriate or polypharmacy may end in adverse drug events, serious adverse reaction even multi organ failure, hospitalization, and death.
Even though concurrent use of assorted medications is termed polypharmacy, the least number of drugs which is preferrable for the elderly to avoid multiple drug regimen prescription is difficult to demarcate inthe scientific documentations available, can be a range betwixt three to six assorted prescribed drugs. Always a pre-determined accepted protocolis better to follow especially in geriatric patients regarding their prescription fashion as it can assure quality in their drug intake. For this, many standard appraisal contrivance have been emerged to estimate thepotentially inappropriate medication (PIM) for geriatric population [1]. Among them the Beer's criteria is the preferred and commonly appliedmodes operandi. These criteria are well defined to evaluate the PIM exclusively and explicitly in elderly above 65years [2]

Beer's criteria states that the drugs which areprescribed inappropriately are categorized into any of the belowcategories:

Category A: Steer clear off drugs.

Category B: Should be within the recommended daily allowance dose.

Category C: Should not be combined with discrete co morbid condition.

The purpose of this study is to analyse the prescription details of elderly in terms of suitability of the drug prescribed, according 
to their demographic status and to detect the inappropriateness in their prescription by the dint of Beer's criteria.

\section{MATERIALS \& METHODS}

This retrospective observational study includes 12 months records of elderly patients from February 2020 to January 2021 in Sree Balaji Medical College Hospital, Chennai, which is 1170 bedded Medical college hospital with all possible tertiary care facilities, in which patients aged 60yrs and above were included. After obtaining institutional ethics committee approval, the study was initiated. A total of 1600 patients records were screened for the study andthe Patient record who were on ventilators and in ICU wards were not included in our study.

\section{RESULTS}

The details of in and outpatient records of 1600 patients were screened,
The demographic characteristics of these patientslike gender, age wise distribution, the reason behind admission and the number of days stay in hospital are shown in Table 1.

The drug prescribed are categorised as described earlier were shown in Table 2.

Multiple drug regimen details like Number of drugs prescribed per day and the preferred route of administration of these drugs are tabulated in Table 3 and $\mathbf{4}$.

Multiple drug regimen details that is potentially inappropriate medicines in them based on Beer's criteria is tabulated in

Table 5.

Percentage of appropriateness and inappropriateness in the prescription is shown in Table 6 and Number of drugs with interaction in Table 7. Type of Interaction in Table 8.

Table 1: Demographic characteristics of case records analysed

\begin{tabular}{|c|c|}
\hline Basic Characteristics & Details of Data obtained \\
\hline \multicolumn{2}{|c|}{ No of case records analysed $(n=1600)$} \\
\hline Male gender & $1040(65 \%)$ \\
\hline Female gender & $560(35 \%)$ \\
\hline \multicolumn{2}{|c|}{ Age in years } \\
\hline $60-69$ & $1152(72 \%)$ \\
\hline 70-79 & $288(18 \%)$ \\
\hline 80-89 & $144(9 \%)$ \\
\hline Above 90 & $16(1 \%)$ \\
\hline \multicolumn{2}{|c|}{ Reason for Admission (Clinical Condition) } \\
\hline Infectious disorder & $448(28 \%)$ \\
\hline Cardiovascular disorder & 304(19\%) \\
\hline Respiratory disorder & $240(15 \%)$ \\
\hline Gastrointestinal disorder & $48(3 \%)$ \\
\hline Musculoskeletal disorder & $288(18 \%)$ \\
\hline Blood disorder & $40(2.5 \%)$ \\
\hline Endocrine disorder & $28(1.75 \%)$ \\
\hline Renal disorder & $100(6.25 \%)$ \\
\hline Others & $104(6.5 \%)$ \\
\hline \multicolumn{2}{|c|}{ Duration of stay } \\
\hline 0-7 days & $880(55 \%)$ \\
\hline 7-14 days & $432(27 \%)$ \\
\hline$>$ 15days & $288(18 \%)$ \\
\hline
\end{tabular}


Table 2: Category of Drugs Prescribed

\begin{tabular}{|c|c|c|c|}
\hline S. No. & $\begin{array}{c}\text { CATEGORY OF THE } \\
\text { PRESCRIBED DRUG }\end{array}$ & NUMBER OF DRUGS & PERCENTAGE \\
\hline 1 & Antibiotics & 1275 & $\mathbf{2 8 . 0 9 \%}$ \\
\hline 2 & Drugs acting on CVS & $\mathbf{5 7 6}$ & $\mathbf{1 2 . 6 9 \%}$ \\
\hline 3 & Drugs acting on RS & $\mathbf{2 4 9}$ & $\mathbf{5 . 4 8 \%}$ \\
\hline 4 & Drugs acting on GIT & 135 & $\mathbf{2 . 9 7 \%}$ \\
\hline 5 & $\begin{array}{c}\text { Analgesics and muscle } \\
\text { relaxants }\end{array}$ & $\mathbf{5 3 2}$ & $\mathbf{1 1 . 7 2 \%}$ \\
\hline 6 & Vitamins and antioxidants & $\mathbf{1 0 6 5}$ & $\mathbf{2 3 . 4 6 \%}$ \\
\hline 7 & Drugs for Diabetes & $\mathbf{4 2 0}$ & $\mathbf{9 . 2 5 \%}$ \\
\hline 8 & Others & $\mathbf{2 8 6}$ & $\mathbf{6 . 3 4 \%}$ \\
\hline
\end{tabular}

Table 3: Multiple Drug Regimen Details

\begin{tabular}{|c|c|c|c|}
\hline S. No. & $\begin{array}{c}\text { NO OF DRUGS PER } \\
\text { PRESCRIPTION }\end{array}$ & NO OF PATIENTS & PERCENTAGE \\
\hline 1 & 5 DRUGS & 808 & $50.5 \%$ \\
\hline 2 & 5-8 DRUGS & 528 & $33 \%$ \\
\hline 3 & $>8$ DRUGS & 264 & $16.5 \%$ \\
\hline
\end{tabular}

Table 4: Preferred Route of Administration of Drug

\begin{tabular}{|c|c|c|c|}
\hline S. No. & $\begin{array}{c}\text { ROUTE OF DRUG } \\
\text { ADMINISTRATION }\end{array}$ & NO OF PATIENTS & PERCENTAGE \\
\hline 1 & PARENTERAL & 1951 & $43 \%$ \\
\hline 2 & ORAL & 2586 & $57 \%$ \\
\hline
\end{tabular}

Table 5: Applying Beer's criteria the multiple drug regimen details that is Potentially Inappropriate Medicines in

\begin{tabular}{|c|c|c|c|}
\hline \multicolumn{4}{|c|}{ Elderly } \\
\hline CATEGORY & DRUGS PRESCRIBED & NUMBER OF DRUGS & PERCENTAGE \\
\hline \multirow{6}{*}{$\begin{array}{c}\text { A } \\
\text { Steer clear off drugs } \\
\text { (Generally, to be avoided in } \\
\text { older patients) }\end{array}$} & NSAIDS & 249 & $53.2 \%$ \\
\hline & Antibiotics & 52 & $11.1 \%$ \\
\hline & Cardiovascular drugs & 21 & $4.4 \%$ \\
\hline & Anticholinergics & 52 & $11.1 \%$ \\
\hline & Vitamins & 109 & $20.29 \%$ \\
\hline & & 468 & \\
\hline $\begin{array}{c}\text { B } \\
\text { Should be within } \\
\text { recommended } \\
\text { daily dose }\end{array}$ & Nil & Nil & $0 \%$ \\
\hline $\begin{array}{c}\text { C } \\
\begin{array}{c}\text { Should not be combined } \\
\text { with discrete co morbid } \\
\text { condition }\end{array} \\
\end{array}$ & Nil & Nil & $0 \%$ \\
\hline
\end{tabular}

Table 6: Percentage of Appropriateness and Inappropriateness in prescription

\begin{tabular}{|c|c|c|c|}
\hline 1 & Appropriate & $\mathbf{9 9 5}$ & $\mathbf{6 2 . 1 8 \%}$ \\
\hline $\mathbf{2}$ & In appropriate & $\mathbf{6 0 5}$ & $\mathbf{3 7 . 8 2 \%}$ \\
\hline
\end{tabular}

Table 7: Drug -Drug Interactions

\begin{tabular}{|c|c|c|c|}
\hline S. No. & Interactions & Number of prescriptions & percentage \\
\hline 1 & $\begin{array}{c}\text { Prescriptions Without } \\
\text { interactions }\end{array}$ & $\mathbf{1 3 8 0}$ & $\mathbf{8 6 . 2 5 \%}$ \\
\hline 2 & $\begin{array}{c}\text { Prescriptions With } \\
\text { interactions }\end{array}$ & $\mathbf{2 2 0}$ & $\mathbf{1 3 . 7 5 \%}$ \\
\hline
\end{tabular}

Table 8: Type of Interaction

\begin{tabular}{|c|c|c|}
\hline Type of interaction & Number of prescriptions & Percentage \\
\hline Minor interaction & $\mathbf{1 8 2}$ & $\mathbf{8 2 . 7 2 \%}$ \\
\hline Moderate interaction & 22 & $\mathbf{1 0 \%}$ \\
\hline Major interaction & 16 & $\mathbf{7 . 2 8} \%$ \\
\hline
\end{tabular}




\section{DISCUSSION}

The medical records of 1600 in-and outpatientswere analysed using pre modelled data collection sheet. After careful analysing, 1040 (65\%) were males and $560(35 \%)$ were female patients. So, major proportion of patients visiting hospital and regimen prescribed and utilized were males and in the age group between 60-69years (72\%). The register shows others were between 70-79 years $(18 \%), 80-89(9 \%)$ and the least comes in the age group above $90(1 \%)$. As the age advances due to the deterioration in the function of metabolism and circulation most of the elderly suffers various chronic diseases and disorders.

In this study, records revealed the treated cases were suffering from infectious disorder (28\%), next in line were cardiovascular system (19\%) and Musculoskeletal disorders (18\%) Respiratory diseases like Lower respiratory infection, Bronchitis, COPD, asthmawere common cause for infection and infection due to Diabetes were also there and this describes the reason for various antibiotic prescriptionof which $43 \%$ of the drugs were administered through parenteral route. Hypertensives and CAD patients were also contributing to the inpatient records.

Golla $\mathrm{P}$ et al study concludes, infectious diseases were shown tobe the topmost reasons for the rise in in patient records and antibiotics were the most common prescribed drug [3]. The issue of multiple drug regimen that is polypharmacy $(49.6 \%)$ is of concern in elderly but as they have multiple ailments and each need specific treatment and to combat the side effect of the prescribed drug vitamin supplementation and gastric irritation prevention drugs were prescribed. All these might be a contributing factor for multiple drug regimen. There are few prescription records which have inappropriate drugs, for example certain antibiotics and NSAIDS were there in the prescription which was not relevant to the diagnosis or can substantiate the reason behind it. This is the special concern which came to highlight from this study. Suggestions to combat this, is by doing proper investigations which is more beneficial to prevent such kinds of inappropriate prescription. For example, necessary culture and sensitivity to be done before prescribing appropriate antibiotics rather treating them with cocktail drugs [4]. Antibiotic stewardship program stress on this and most of the time, considering the delay in patient arrival, that is patient was coming to the hospital in acute severe condition, so waiting for the sensitivity reports will be further worsening the condition and delay in antibiotics may provoke septicaemia as well. Educating the public regarding their role to seek medical 
advice at the earliest is also a part to prevent such events.

Drug-drug interactions are the highest therapeuticissues identified. Many elderlies suffer serious adverse effect and $7.28 \%$ of major interaction were noted and this need correction from physician as well as patient side $[5,6]$. Elderly is fond of vitamin supplements whether they are in need or not but satisfied by the colourful grains of the capsule which is also a concern. Clinician skill, expertise can obviously uplift the scenario and help to overcome these kinds of interactions. The in-patient data shows, the patients who are hospitalised for less than 7 days: $880(55 \%)$, 7-14days:432(27\%), >14 days 288(18\%). The morbidity due to ignoring drug-drug interaction might have an implication on the quality health life of patient, the need for bird view evaluation of these events is mandatory to prevent them. Kojima et al study, have contributed to detect risk factors involved in patients who had prescription with drug interactions in elderly [7], this study even though was not focused on that the major drug interaction in our study out of 220 inappropriate prescription is $17.28 \%$ which includes Major and moderate interaction. The data base used to evaluate the drug interaction is Micromedex drug data base. This categorized the drug-drug interaction into major, moderate, and minor based on their severity. Studies revealed drug interaction can even contribute to depression in elderly [8].

According to Beer's criteria, drugs which are prescribed inappropriately are categorized into any of the below categories:

Category A: Steer clear off drugs.

Category B: Should be within the recommended daily allowance dose.

Category C: Should not be combined with discrete co morbid condition.

In category A 468 drugs were enlisted under this category. NSAIDs (diclofenac,

Etoricoxib) prescribed to $33.2 \%$, cardiovascular drugs (prazosin, spironolactone, chlorthalidone) to $4.4 \%$, vitamin supplements (multimineral capsules) to $32 \%$ of patients form most potentially inappropriate medicines in category A.

\section{CONCLUSION}

The study once more had added that still polypharmacy is high and essential steps are needed for reducing avoidable reasons. This further concludes thatstill more cooperation is needed across disciplines and apart from that educating the patients to sought medical attention at the earliest possible. Adequate refreshing training regarding the prescription writing pattern with special emphasis on avoidable drugs in co morbid conditions need to be 
highlighted in general practice as well as in internship programmes.

FUNDING: Nil

CONFLICT OF INTEREST: Nil REFERENCES

[1] Swathi B, BHAVIKA D. Pattern of medication use among elderly patients attending medicine department in a tertiary care hospital in India. Asian J. Pharm. Clin. Res., 2016; 9(6): 266-9.

[2] Goudanavar P, Jacob J, Krishna MS, John SE, Keerthi Y. A Prospective study on medication prescribing pattern for geriatric patients in a tertiary care teaching Hospital. J. Pharm Res., 2015; 1: 98.

[3] Golla P, Bheemathati RR, Ramesh SP, Edara N, Adepu R. Prescribing Pattern of Medications in Geriatric Patients in a South Indian Tertiary Care Teaching Hospital. Indian Journal of Pharmacy Practice., 2020; 13(1): 69.

[4] Sarkar S. Geriatric Polypharmacy: A Growing Epidemic. How to
Prevent It? J. adv. med. med. res., 2017; 24: 1-1.

[5] Pretorius RW, Gataric G, Swedlund SK, Miller JR. Reducing the risk of adverse drug events in older adults. Am Fam Physician., 2013; 1; 87(5): $331-6$.

[6] Mizumoto J. Drug Overflow: Polypharmacy-Related Adverse Drug Reaction Triggered by Hospitalization. Am. J. Med. 2021; 1; 134(3): e207-8.

[7] Kojima T, Matsui T, Suzuki Y, Takeya Y, Tomita N, Kozaki K, Kuzuya M, Rakugi H, Arai H, Akishita M. Risk factors for adverse drug reactions in older inpatients of geriatric wards at admission: multicentre study. Geriatr. Gerontol Int., 2020; 20(2): 144-9.

[8] Srivatsa S, Bose D, Sushma M, Jayanthi CR. A prospective cohort study to evaluate the correlates of poly-pharmacy and its association with depression among elderly patients. Internatl J Basic \& Clin. Pharmacol., 2017; 5(5): 1984-90. 